\title{
Low air humidity during cultivation promotes stomatal closure ability in rose
}

\author{
D. Fanourakis ${ }^{1}$, H. Giday ${ }^{2,3}$, B. Hyldgaard ${ }^{2,4}$, D. Bouranis ${ }^{5}$, O. Körnerer, ${ }^{6,7}$ and C.-O. Ottosen ${ }^{2}$ \\ ${ }^{1}$ Giannakakis SA, Export Fruits and Vegetables, Tympaki, Greece \\ 2 Department of Food Science, Aarhus University, Årslev, Denmark \\ ${ }^{3}$ Horticulture and Product Physiology Group, Wageningen University, Wageningen, The Netherlands \\ ${ }^{4}$ Department of Bioscience, Aarhus University, Aarhus C, Denmark \\ ${ }^{5}$ Plant Physiology and Morphology Laboratory, Crop Science Department, Agricultural University of Athens, Athens, Greece \\ ${ }^{6}$ Department of Plant Technology, AgroTech, Danish Technological Institute, Taastrup, Denmark \\ ${ }^{7}$ Leibniz-Institute of Vegetable and Ornamental Crops (IGZ), Großbeeren, Germany
}

\section{Summary}

In greenhouse horticulture, evaporative demand varies between seasons. For instance, plants are typically exposed to low relative air humidity $(\mathrm{RH})$ during summer, whereas elevated RH prevails in winter. Since high RH during cultivation impairs stomatal functioning, some opposite changes might be expected, when plants are subjected to long-term low RH. To investigate this, Rosa hybrida 'Pasadena' was cultivated at 40,60 or $90 \%$ RH. Plant performance, transpiration, stomatal closing ability and anatomy were recorded. As RH increased from 40 to $60 \%$ as well as from 60 to $90 \%$, plants showed larger leaf area and thinner leaves. Plant water loss was mainly determined by ambient RH in the growing environment, with stomatal conductance $\left(g_{s}\right)$ being of secondary importance. With increasing $\mathrm{RH}$, plant transpiration declined at growth environment. Larger stomata were found at $\mathbf{9 0 \%} \mathbf{R H}$, as compared to 40 or $\mathbf{6 0 \%}$. Stomatal physiology was considerably affected by $90 \% \mathrm{RH}$, including reduced $g_{s}$ oscillations within the photoperiod, attenuated opening response following dark/light transition, as well as reduced closing response upon darkening. The plants cultivated at $90 \% \mathrm{RH}$ had a reduced ability to control water loss upon water deprivation, compared to those grown at $60 \%$. In contrast, cultivation at $\mathbf{4 0 \%} \mathrm{RH}$ resulted in stomata, which were much more responsive to water stress, compared to $60 \%$ RH-grown plants. This superiority was dual: lower transpiration rate combined with less severe leaf drying to induce stomatal closure. In conclusion, low RH during cultivation, which is typical during summer, leads to thicker leaves with very responsive stomata.

Keywords

evaporative demand, stomata, transpiration, vapour pressure deficit

\section{Abbreviations}

[ABA], abscisic acid concentration; ABA, abscisic acid; $\mathrm{g}_{\mathrm{s}}$, stomatal conductance; LMR, leaf mass ratio; PPFD, photosynthetic photon flux density; RH, relative air humidity; RWC, relative water content; SLA, specific leaf area; VPD, vapour pressure deficit.

\section{Significance of this study}

What is already known on this subject?

- In protected cultivation, relative air humidity (RH) varies depending on the season. It is often high ( $\geq 85 \%$ ) during the winter, whereas low $(40 \%)$ $\mathrm{RH}$ is typical during the summer period. It is welldocumented that high RH during leaf expansion impairs stomatal functioning, whereas the respective effects of low RH have received limited attention.

What are the new findings?

- Stomata formed at high RH showed reduced closing response upon darkening or water deprivation. Instead, cultivation at $40 \% \mathrm{RH}$ resulted in stomata, which were much more responsive to water stress. Therefore, RH (range 40 to 90\%) during leaf expansion is decisive for stomatal closing ability.

What is the expected impact on horticulture?

- The seasonal variation in RH affects stomatal regulation of water loss, and in this way also bears implications for the keeping quality of ornamentals grown in protected cultivation.

\section{Introduction}

Effective regulation of transpiration, owing to functional stomata, is essential for plant survival, especially under conditions of water deficit (Sellin et al., 2014; Fanourakis et al., 2014). Stomatal ability to respond to closing signals (e.g., low water potential or light-dark transition) is determined by the environment during leaf expansion (Aliniaeifard and Van Meeteren, 2013; Carvalho et al., 2016). Consequently, plant survival during post-harvest largely depends on the prevailing environmental conditions during cultivation (Fanourakis et al., 2016).

Environmental conditions vary considerably depending on the season. Although less prominent as compared to open field (Poorter et al., 2016), these differences in climate are still considerable in protected cultivation, with potential consequences for plant survival when these are moved outdoors or even in another (indoor) environment (Rezaei Nejad and Van Meeteren, 2007). A typical example of seasonal climate variation is relative air humidity (RH) (Mortensen and Gislerød, 2005). In temperate climates, greenhouse air is 
often humid $(\mathrm{RH} \geq 85 \%)$ during winter months, whereas $\mathrm{RH}$ levels below $40 \%$ are often observed during summer.

Over the past decade, several studies were focused on stomatal functioning following cultivation in elevated $\mathrm{RH}$ ( $\geq 85 \%$ ) and, thus, the respective effects are well-documented (Fanourakis et al., 2016). Plants cultivated under constant high RH frequently express a rapid wilting trait when exposed to lower RHs $(\leq 60 \%)$ (Carvalho et al., 2015; Arve et al., 2016). The incidence of adverse water relations of these plants has been mainly linked to less functional stomata (Arve and Torre, 2015; Aliniaeifard and Van Meeteren, 2016). Intuitively, one might assume that low (40\%) RH exerts a contrasting effect to high RH (thus promotive) on stomatal functionality. However, the effects of long-term low RH on stomatal functioning have been addressed by a limited number of studies, where antithetical outcomes have been presented depending on the species (Fanourakis et al., 2017; Hõrak et al., 2017). The dual aim of this work was to analyse the water relations in Rosa hybrida grown in different RH levels $(40,60$, and $90 \%)$ and assess the effect of RH on stomatal closing ability in response to water stress.

\section{Materials and methods}

\section{Plant material and growing conditions}

One-month old plants of pot rose 'Pasadena' (Rosa hybrida L.) were obtained from a commercial nursery (Rosa Danica, Marslev, Denmark). Cultivar selection was based on a preliminary study, indicating sensitivity to high RH (i.e., attenuated stomatal closing ability when grown under humid conditions). Pots $(0.55 \mathrm{~L})$ were filled with a mixture of peat and perlite (9:1, v/v; Meegaa substrates BV, Rotterdam, The Netherlands). Upon transfer, plants were pruned leaving two nodes on the main shoot, each bearing a leaf and its axillary bud. From those buds, the most vigorous one was kept (formed the shoot that was assessed), whereas the other one was removed. The plants were then moved to three growth chambers (MB-teknik, Brøndby, Denmark), set at different levels of RH [i.e., $40 \%$ (dry), $60 \%$ (moderate) or $90 \%$ (humid)]. The remaining environmental variables were identical among the three chambers. Air temperature was set to $20^{\circ} \mathrm{C}$, resulting in water vapour pressure deficits (VPD) of $1.41,0.94$ and $0.23 \mathrm{kPa}$, respectively. Light level was set at $200 \mu \mathrm{mol} \mathrm{m}^{-2} \mathrm{~s}^{-1}$ photosynthetic photon flux density (PPFD; determined by LI-250A, LI-COR, Lincoln, NE, USA) for $18 \mathrm{~h}$ per day, and was supplied by fluorescence lamps (HQIBT 400W/D pro, Slovakia). Carbon dioxide concentration was set to $400 \mu \mathrm{mol} \mathrm{mol}{ }^{-1}$. Climate data was automatically logged (Datataker, Thermo Fisher Scientific Australia Pty Ltd., Scoresby, Australia) throughout the experiment by sensors placed at $60 \mathrm{~cm}$ (corresponding to the top of fully grown plants). Plants were daily watered with a nutrient solution optimised for rose, maintaining potting-media moisture at or near full-water-holding-capacity. Electrical conductivity and $\mathrm{pH}$ were daily monitored and adjusted to $2 \mathrm{mS} \mathrm{cm}^{-1}$ and 5.5, respectively.

After four weeks in the climate chambers, measurements were performed on fully developed plants (defined as bearing at least two flower buds with cylindrical shape and pointed tip). Sampled leaves were young, fully expanded, and grown under direct light. Replicate leaves were collected using separate plants. In all cases, the time between sampling and the start of the evaluation did not exceed $15 \mathrm{~min}$.

\section{Leaf morphological components}

To evaluate the effect of ambient humidity on leaf morphological components, leaf area, together with leaf and aboveground dry masses were recorded. Leaf area was determined with a leaf area meter (LI-COR Model Li-3100, LICOR, Lincoln, NE, USA), and dry weight was assessed after drying the tissue for $48 \mathrm{~h}$ at $80^{\circ} \mathrm{C}$ in a drying cabinet. Specific leaf area (SLA; leaf area/leaf mass) and leaf mass ratio (LMR; leaf mass/plant mass) were calculated. The measurements were conducted in seven plants per treatment.

\section{Diurnal variation in gas exchange}

Diurnal changes in stomatal conductance $\left(\mathrm{g}_{\mathrm{s}}\right), \mathrm{CO}_{2}$ assimilation rate and transpiration rate were examined in situ in plants at the three different RH levels. Terminal leaflets of the first and second five-leaflet leaves (counting from the apex) were used. Continuous measurements (every $3 \mathrm{~min}$ ) were performed over a diurnal cycle, by using a portable infrared gas analyser (IRGA, CIRAS-2, PP systems, Amesbury, MA, USA) in attached leaves of intact plants. Environmental conditions in the cuvette were identical to that of the growing conditions (i.e., $200 \mu \mathrm{mol} \mathrm{m}^{-2} \mathrm{~s}^{-1}$ PPFD for $18 \mathrm{~h}$ followed by $6 \mathrm{~h}$ darkness, $20^{\circ} \mathrm{C}$ temperature, $400 \mu \mathrm{mol} \mathrm{mol}^{-1} \mathrm{CO}_{2}$ concentration, and 40,60 or $90 \% \mathrm{RH}$ depending on the treatment). Four $(60 \% \mathrm{RH})$ or five ( 40 and $90 \% \mathrm{RH})$ leaflets were evaluated per atmospheric humidity.

\section{Plant water loss}

The effect of different levels of RH on whole plant transpiration was evaluated at growth conditions. During a fiveday period, pot water loss was daily determined by weighing ( \pm 0.1 g; MXX-2001; Denver Instruments, Bohemia, NY, USA) the pots two times a day (time 0 and $18 \mathrm{~h}$ after the onset of the light period), as well as the supplied nutrient and drainage solutions. Growth-media evaporation was assessed daily in four pots without plants, but with identical media water content to the pots containing plants. Direct evaporation from the media was subtracted from pot water loss to determine plant water loss. Plant transpiration rate was calculated per unit leaf area and was assessed in seven intact plants per treatment. The treatments were compared based on the average day time and night time transpiration rates over the complete five-day period.

\section{Stomatal density, length and width}

The effect of relative humidity during leaf expansion on stomatal length (i.e., longest diameter), width (i.e., shortest diameter), and density (i.e., number per unit leaf area) was determined. The silicon rubber impression technique was employed (elite HD+, Zhermack, Badia Polesine, Italy; Giday et al., 2013b) using a lateral leaflet of the first penta-foliate leaf (counting from the apex). The sampling area $(1 \times 1 \mathrm{~cm})$ was located midway the leaflet base and tip, as well as between the midrib and lateral margin. Images were acquired using an optical microscope (Leitz Aristoplan; Ernst Leitz Wetzlar GmbH, Wetzlar, Germany) connected to a digital camera (Nikon DXM1200; Nikon Corp., Tokyo, Japan). As rose is a hypostomatous species (Fanourakis et al., 2013), only the abaxial (lower) leaflet surface was assessed. Stomatal length and width were determined on ten randomly selected stomata (magnification $\times 200$ ), while stomatal density was counted on five non-overlapping interveinal fields of view per leaflet (magnification $\times 100$ ). Image processing was performed with the ImageJ software program (Rasband, 2011). Ten (stomatal density) or six (stomatal size) leaflets were assessed in all three treatments. 
TABLE 1. Effect of relative air humidity (RH) during cultivation on biomass accumulation and gas exchange parameters of pot rose 'Pasadena'. Data refer to at least four (gas exchange) or eight (biomass) replications. SLA, specific leaf area; LMA, leaf mass ratio.

\begin{tabular}{|c|c|c|c|c|c|c|c|}
\hline $\mathrm{RH}(\%)$ & $\begin{array}{l}\text { Above ground } \\
\text { dry mass }(\mathrm{g})\end{array}$ & $\begin{array}{l}\text { Leaf area } \\
\qquad\left(\mathrm{cm}^{2}\right)\end{array}$ & $\begin{array}{c}\text { SLA } \\
\left(\mathrm{cm}^{2} \mathrm{~g}^{-1}\right)\end{array}$ & $\begin{array}{l}\text { LMR } \\
\left(g^{-1}\right)\end{array}$ & $\begin{array}{c}\mathrm{CO}_{2} \text { assimilation rate } \\
\left(\mu \mathrm{mol} \mathrm{m} \mathrm{m}^{-2} \mathrm{~s}^{-1}\right)\end{array}$ & $\begin{array}{c}\text { Stomatal } \\
\text { conductance } \\
\left(\mathrm{mmol} \mathrm{m}^{-2} \mathrm{~s}^{-1}\right)\end{array}$ & $\begin{array}{l}\text { Transpiration } \\
\left(\mathrm{mmol} \mathrm{m} \mathrm{m}^{-2} \mathrm{~s}^{-1}\right)\end{array}$ \\
\hline 40 & $11.4^{a}$ & $735^{a}$ & $151^{a}$ & $0.40^{a}$ & $4.67^{a}$ & $65^{\mathrm{a}}$ & $0.91^{c}$ \\
\hline 60 & $10.9^{a}$ & $778^{b}$ & $170^{b}$ & $0.42^{\mathrm{a}}$ & $5.30^{\mathrm{b}}$ & $88^{b}$ & $0.87^{\mathrm{b}}$ \\
\hline 90 & $11.6^{a}$ & $816^{c}$ & $180^{\circ}$ & $0.39^{a}$ & $6.70^{\circ}$ & $197^{\circ}$ & $0.76^{a}$ \\
\hline Significance & - & * & * & - & ** & ** & * \\
\hline
\end{tabular}

* Significant at the 0.05 probability level.

** Significant at the 0.01 probability level.

\section{Stomatal responsiveness to desiccation}

Stomatal responsiveness was evaluated by exposing detached leaflets to dehydrating conditions. First and second five-leaflet leaves (counting from the apex) were sampled. Terminal leaflets with long petioles $(>2 \mathrm{~cm})$ were selected, facilitating both rehydration (see below) and handling (i.e., preventing contact with the leaflet lamina) procedures. Leaflets were detached at the same time of the day (i.e., $2 \mathrm{~h}$ following the onset of the light period), re-cut by submerging their petiole under water (to prevent cavitation of xylem vessels that were opened by cutting) and placed in flasks filled with degassed water. The leaflets were incubated at $21^{\circ} \mathrm{C}, \sim 100 \%$ RH (i.e., VPD close to 0 ), and under $15 \mu \mathrm{mol} \mathrm{m}^{-2} \mathrm{~s}^{-1}$ PPFD for $1 \mathrm{~h}$ to establish their maximum fresh weight (Fanourakis et al., 2013). The leaflets were then placed on a bench (downfacing abaxial surface) in the test room, and the transpiration rate was recorded for $4 \mathrm{~h}$ by gravimetry $( \pm 0.0001 \mathrm{~g}$; Mettler AE 200, Giessen, Germany). Measurement frequency was $5(0-1 \mathrm{~h}), 10(1-2 \mathrm{~h}), 15(2-3 \mathrm{~h})$, and $30(3-4 \mathrm{~h}) \mathrm{min}$. Preliminary work comparing transpiration rates between leaves with either intact or sealed (by using paraffin wax) petioles indicated that water loss through the petiole cut end was negligible, and thus petioles were not sealed during measurements. Test room conditions were air temperature of $21^{\circ} \mathrm{C}$, RH equal to $50 \%$, and $50 \mu \mathrm{mol} \mathrm{m}^{-2} \mathrm{~s}^{-1}$ PPFD provided by fluorescent lamps (T5 fluorescent lamp; GE lighting, Cleveland, OH, USA). As an indication of air velocity, the rate of evaporation from two glass beakers was recorded in the test room during measurements. The evaporation rate of

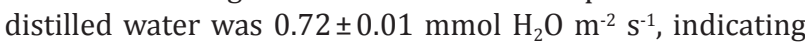
adequate air circulation. Different treatments were assessed simultaneously. At the end of the measurement, leaflet area and dry weight were determined, as described earlier. Leaflet relative water content (RWC) was calculated using the following equation:

$$
\mathrm{RWC}=\frac{\text { fresh weight }- \text { dry weight }}{\text { saturated fresh weight }- \text { dry weight }} \times 100
$$

Stabilization RWC was defined as the RWC at which the transpiration rate stabilized (Giday et al., 2013b). In brief, the stable transpiration rate was defined as the average of the three consecutive points that do not significantly differ, while stabilization RWC was taken as the RWC where the first of these three points was noted. Measurements were carried out on 12 leaflets per treatment.

\section{Data analysis}

Data were subjected to two-way analysis of variance (ANOVA) using IBM SPSS Statistics for Windows, Version
24.0. (IBM Corp., Armonk, NY, USA). Variance homogeneity was tested using Levene's test and data were log-transformed, if necessary. Tukey's multiple range tests were used to identify significant differences between mean values at the $5 \%$ significance level.

\section{Results}

\section{Leaf morphological components}

RH during cultivation affected neither aboveground plant mass nor its partitioning to the leaves, however, at higher RH the plants had larger leaf area and thinner leaves (Table 1).

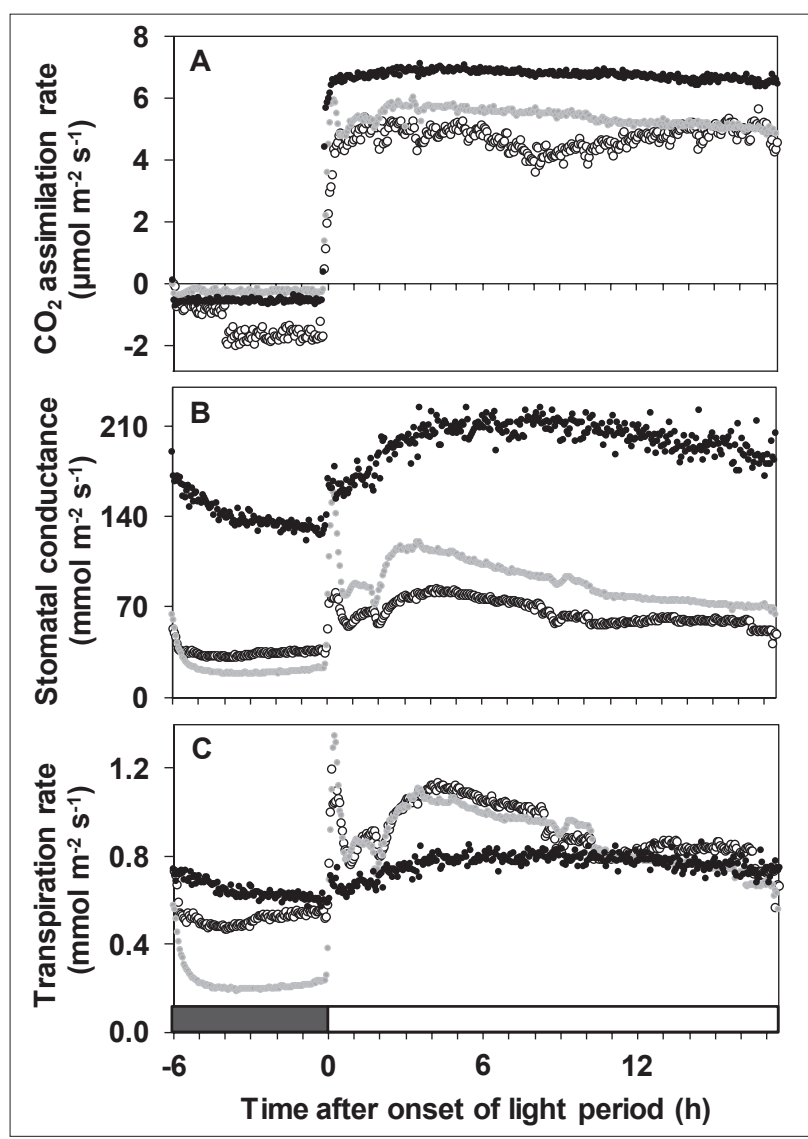

FigURE 1. Diurnal course of $\mathrm{CO}_{2}$ assimilation rate (A), stomatal conductance (B), and transpiration rate (C) in pot rose 'Pasadena' grown and assessed at 40\% (white), 60\% (grey) or $90 \%$ (black) relative air humidity. The grey bar indicates the dark period, and time is following the onset of the light period. Measurements were conducted in the climate chamber and on fully expanded attached leaves. 
TABLE 2. Effect of relative air humidity (RH) during cultivation on stomatal closure in response to darkness and on stomatal opening in response to light of pot rose 'Pasadena'. Data refer to at least four replications. Data are derived from Figure 1B.

\begin{tabular}{lcccc}
\hline $\mathrm{RH}(\%)$ & $\begin{array}{c}\text { Duration of stomatal closure } \\
(\mathrm{min})\end{array}$ & $\begin{array}{c}\text { Rate of stomatal closure }^{1} \\
\left(\mathrm{~min}^{-1}\right)\end{array}$ & $\begin{array}{c}\text { Duration of stomatal } \\
\text { opening }^{2}(\mathrm{~min})\end{array}$ & $\begin{array}{c}\text { Rate of stomatal } \\
\text { opening }^{2}\left(\mathrm{~min}^{-1}\right)\end{array}$ \\
\hline 40 & $16^{\mathrm{a}}$ & $0.75^{\mathrm{c}}$ & $20^{\mathrm{b}}$ & $2.0^{\mathrm{b}}$ \\
60 & $60^{\mathrm{b}}$ & $0.67^{\mathrm{b}}$ & $16^{\mathrm{a}}$ & $8.8^{\mathrm{c}}$ \\
90 & $280^{\mathrm{c}}$ & $0.18^{\mathrm{a}}$ & $320^{\mathrm{c}}$ & $0.3^{\mathrm{a}}$ \\
\hline Significance & ${ }^{* *}$ & ${ }^{*}$ & ${ }^{*}$ & ${ }^{*}$ \\
\hline
\end{tabular}

1 Following darkening.

2 Following the onset of the photoperiod.

* Significant at the 0.05 probability level.

** Significant at the 0.01 probability level.

*** Significant at the 0.001 probability level.

\section{Diurnal variation in gas exchange}

The $\mathrm{CO}_{2}$ assimilation rate $\left(\mathrm{P}_{\mathrm{n}}\right)$ was the highest at $90 \% \mathrm{RH}$, and the lowest at $40 \%$ RH (Figure 1A; see also Table 1). Variation during the light period in $\mathrm{P}_{\mathrm{n}}$ was relatively small. Similarly, to $P_{n}$, the $g_{s}$ was favoured by a stepwise increase in RH in both light and dark periods (Figure 1B; see also Table 1). Upon darkness imposition, $g_{s}$ rapidly decreased at 40 and 60\%, whereas the respective decrease was not only slower but also longer in duration [lasting $6 \mathrm{~h}$ (i.e., the whole dark period)] at $90 \%$ RH (Figure 1B; Table 2). Thus, gs remained very high during the night period at $90 \% \mathrm{RH}$. At the onset of the light period, $\mathrm{g}_{\mathrm{s}}$ rapidly increased at 40 and $60 \% \mathrm{RH}$, whereas the respective rate was slow at high RH (Figure 1B; Table 2). A large oscillation in $\mathrm{g}_{\mathrm{s}}$ during the light period was observed in leaves expanded at 40 and $60 \%$, whereas nearly no oscillation was noted in leaves of plants grown at $90 \% \mathrm{RH}$ (Figure 1B). The $\mathrm{g}_{\mathrm{s}}$ during the light period showed a peak in the first hours, while the lowest value was always observed at the end of the light period in leaves grown at 40 and $60 \% \mathrm{RH}$. This trend was very weak (nearly absent) in leaves at $90 \% \mathrm{RH}$.

Unlike $\mathrm{CO}_{2}$ assimilation rate and $\mathrm{g}_{\mathrm{s}}$, an increase of $\mathrm{RH}$ led to a decrease in leaf transpiration rate over the $24 \mathrm{~h}$ period (Table 1; see also Figure 1C). This was driven entirely by the light period (mainly during $0-10 \mathrm{~h}$ ), as leaves at $40 \%$ transpire more than $60 \%$, followed by $90 \%$ (Figure 1C). During the night time period, leaf transpiration rate was the highest at $90 \%$ followed by $40 \%$, with the lowest value noted at $60 \% \mathrm{RH}$. The difference between day time and night time leaf transpiration, as well as the oscillation in transpiration during the light period were very prominent at 40 and $60 \%$, whereas these were very weak at $90 \% \mathrm{RH}$ (Figure 1C).

\section{Plant water loss}

An increased RH during cultivation led to a decrease in plant water loss in both light and dark periods (Figure 2).
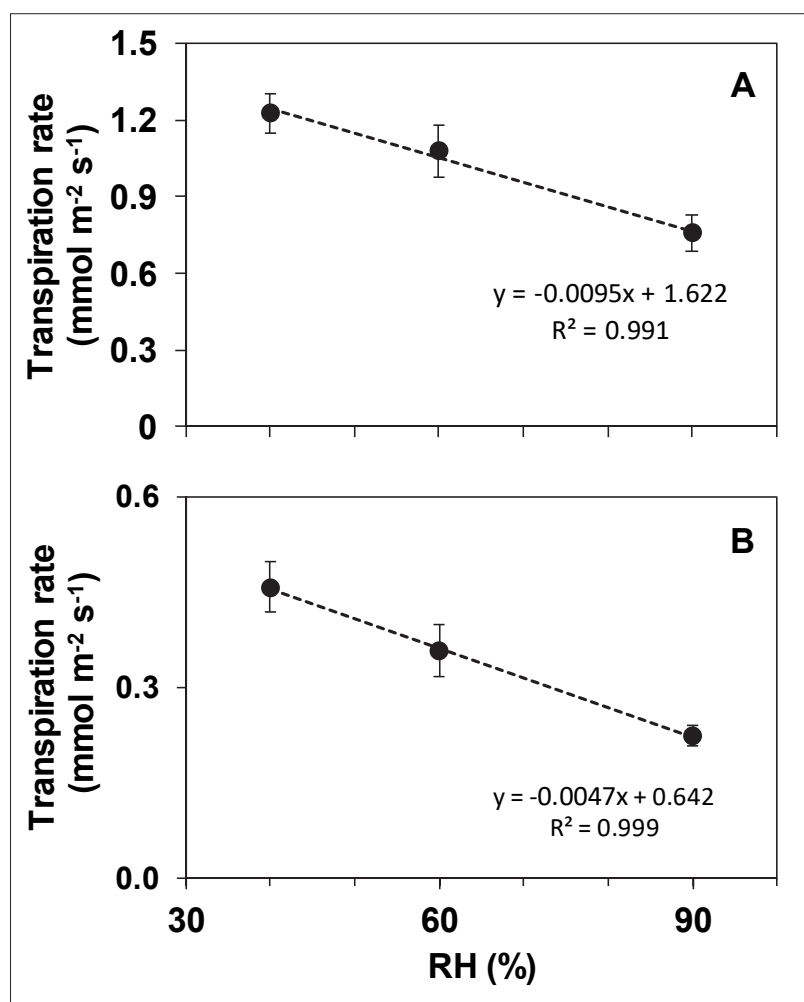

FIGURE 2. Day time (A) and night time (B) plant transpiration rate of pot rose 'Pasadena' grown at different levels of relative air humidity (RH). Measurements were conducted in the climate chamber using fully-grown intact plants (at least two flower buds with cylindrical shape and pointed tip) $(n=7)$. The difference in the y-axis scale should be noted.

TABLE 3. Effect of relative air humidity (RH) during cultivation on stomatal density, length, width, and length to width ratio of pot rose 'Pasadena'. Ten (density) and six (size) fully expanded leaflets were evaluated per treatment.

\begin{tabular}{lcccc}
\hline $\mathrm{RH}(\%)$ & $\begin{array}{c}\text { Stomatal density } \\
\left(\mathrm{mm}^{-2}\right)\end{array}$ & $\begin{array}{c}\text { Stomatal length } \\
(\mu \mathrm{m})\end{array}$ & $\begin{array}{c}\text { Stomatal width } \\
(\mu \mathrm{m})\end{array}$ & $\begin{array}{c}\text { Stomatal length to } \\
\text { width ratio }^{1}\end{array}$ \\
\hline 40 & 70.1 & $33.1^{\mathrm{a}}$ & $18.4^{\mathrm{a}}$ & $1.8^{\mathrm{b}}$ \\
60 & 68.4 & $35.0^{\mathrm{a}}$ & $19.1^{\mathrm{a}}$ & $1.8^{\mathrm{b}}$ \\
90 & 66.0 & $39.4^{\mathrm{b}}$ & $23.2^{\mathrm{b}}$ & $1.7^{\mathrm{a}}$ \\
\hline Significance & - & ${ }^{* * *}$ & ${ }^{* *}$ & ${ }^{* * *}$ \\
\hline
\end{tabular}

1 Indicative of shape.

*** Significant at the 0.001 probability level. 
TABLE 4. Effect of relative air humidity $(\mathrm{RH})$ during cultivation on stomatal closure in response to desiccation of pot rose 'Pasadena'. Data refer to 12 replications. The desiccation curve is provided in Figure 3.

\begin{tabular}{|c|c|c|c|c|c|}
\hline $\mathrm{RH}(\%)$ & $\begin{array}{l}\text { Transpiration rate } \\
10 \mathrm{~min} \\
\left(\mathrm{mmol} \mathrm{m}^{-2} \mathrm{~s}^{-1}\right)\end{array}$ & $\begin{array}{l}\text { Stabilization relative } \\
\text { water content } \\
\text { (RWC; \%) }\end{array}$ & $\begin{array}{l}\text { Transpiration rate at } \\
\text { stabilization RWC } \\
\left(\mathrm{mmol} \mathrm{m}^{-2} \mathrm{~s}^{-1}\right)\end{array}$ & $\begin{array}{c}\text { RWC } 4 \mathrm{~h} \\
(\%)\end{array}$ & $\begin{array}{c}\text { Change in } \\
\text { transpiration rate } \\
\text { (stable relative to initial; \%) }\end{array}$ \\
\hline 40 & $0.85^{\mathrm{a}}$ & $83.7^{c}$ & $0.07^{a}$ & $79.7^{c}$ & $-92^{c}$ \\
\hline 60 & $0.83^{a}$ & $64.8^{\mathrm{b}}$ & $0.17^{b}$ & $53.1^{\mathrm{b}}$ & $-80^{b}$ \\
\hline 90 & $1.10^{b}$ & $31.1^{\mathrm{a}}$ & $0.26^{c}$ & $26.4^{\mathrm{a}}$ & $-76^{c}$ \\
\hline Significance & $* *$ & $* * *$ & $* *$ & $* * *$ & * \\
\hline
\end{tabular}

* Significant at the 0.05 probability level.

** Significant at the 0.01 probability level.

*** Significant at the 0.001 probability level.

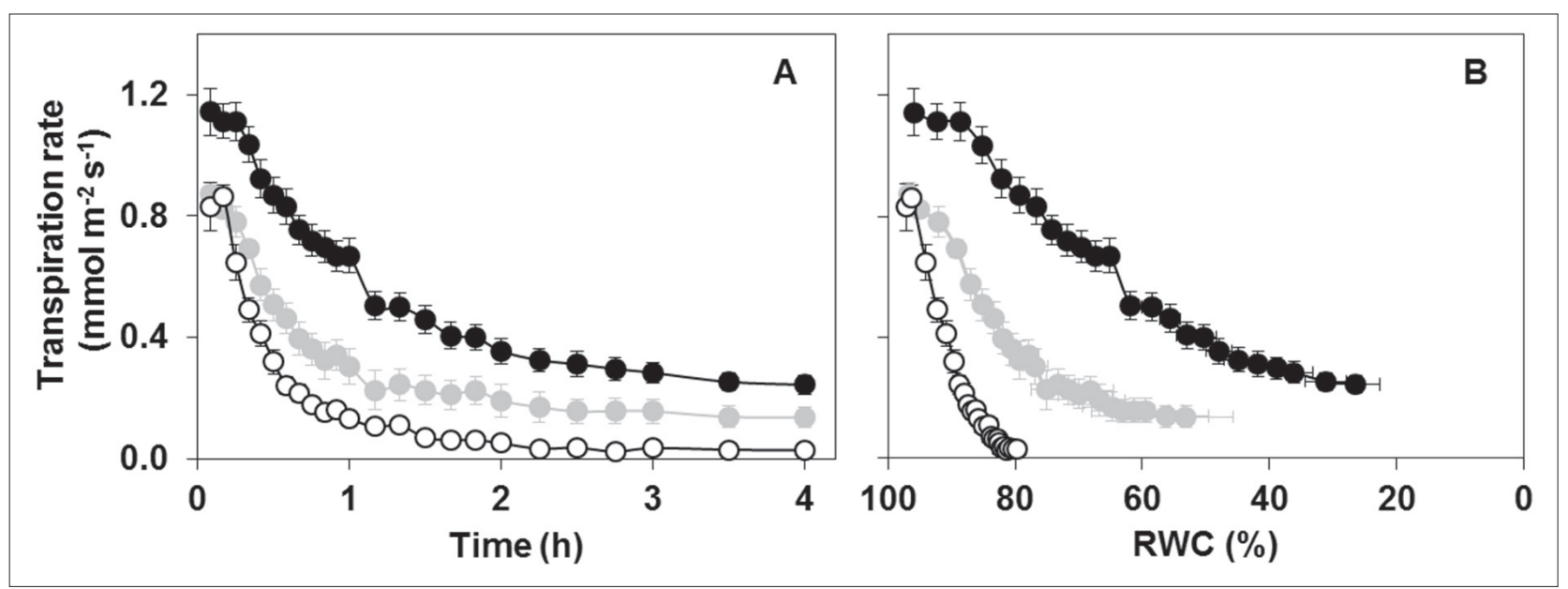

FIGURE 3. Transpiration rate as a function of time (A) and relative water content (RWC; B) during leaflet desiccation in pot rose 'Pasadena' grown at 40\% (white), $60 \%$ (grey) or $90 \%$ (black) relative air humidity. Values are the mean of 12 leaves \pm sem.

\section{Stomatal density, length and width}

Stomatal density was independent of RH level $(p=0.088$; Table 3). Stomata were longer, wider and more rounded at $90 \% \mathrm{RH}$, as compared to 40 and $60 \% \mathrm{RH}$ (Table 3). Low (40\%) RH did not affect stomatal size or shape, as compared to moderate $(60 \%)$ RH (Table 3).

\section{Stomatal responsiveness to desiccation}

To investigate the effect of $\mathrm{RH}$ on the stomatal closing ability, detached leaves were exposed to desiccation. Ten to 15 min following the onset of desiccation, transpiration rate decreased with time in all treatments, reaching the minimum values $2 \mathrm{~h}$ after start (Figure 3A). For the first $10 \mathrm{~min}$ of desiccation, leaves expanded at 40 or $60 \% \mathrm{RH}$, had the same transpiration rate (Figure 3A; see also Table 4). For the remaining desiccation period, there was a clear distinction between the three treatments. Leaves expanded at $40 \% \mathrm{RH}$ had the lowest transpiration rate, leaves developed at $60 \%$ RH showed medium values, while leaves excised from plants cultivated at $90 \%$ RH had the highest rate of transpiration (Figure 3A).

The differences between the three treatments were even more prominent, when the transpiration rate was plotted against leaflet RWC (Figure 3B). It here becomes apparent that the leaf weight loss (i.e., the decrease in RWC) that is required to induce stomatal closure strongly depends on the RH level during leaf expansion (Figure 3B; see also Table 4). Less severe leaf drying is able to promote stomatal closure in plants grown at $40 \%$, compared to $60 \%$ RH-grown plants. Contrary to this, leaves excised from plants grown at $90 \% \mathrm{RH}$ need to be severely dried (i.e., reach very low RWC values) to cause stomatal closure. The level of RH also affected the degree of stomatal closure. Leaves grown at $40 \%$ showed the largest decrease in transpiration rate, while leaves grown at $90 \%$ had the smallest decrease (Table 4 ).

\section{Discussion}

Environmental conditions affect stomatal functioning, which in turn determines the ability of the plants to cope with abiotic stress (reviewed by Fanourakis et al., 2016). Climate in protected cultivation typically follows a seasonal pattern (Mortensen and Gislerød, 2005), where humid conditions generally prevail during winter, whereas air becomes dry during summer. Although several studies were focused on stomatal physiology of plants developed at high RH (Carvalho et al., 2015; Arve et al., 2016), experimental data clarifying the role of low $\mathrm{RH}$ as a factor influencing stomatal functioning are lacking. This is the first study that also includes the effect of low RH during leaf development on stomatal functionality in rose.

\section{Cultivation RH and leaf thickness are inversely related}

The RH during cultivation exerted a minor effect on plant (above ground) biomass and its allocation to the leaves (Table 1). Instead, a stepwise increase in cultivation RH (i.e., a decrease in evaporative demand) led to higher leaf area and thinner leaves (i.e., higher SLA; Table 1). Previous studies were limited to the comparison between moderate and high $\mathrm{RH}$, showing that high RH supressed leaf thickness in several species (Zhang et al., 2015). We show that the promotive effect of RH on SLA is also maintained at low RH (Table 1). The mechanism underlying the RH effect on SLA has not yet been elucidated. 
SLA expresses the expected return of previously captured resources (Poorter et al., 2012). Accordingly, high-SLA leaves are produced in resource-rich environments, whereas low-SLA leaves are found under resource-poor conditions, where retention of captured reserves gets priority. To this end, an increase in RH creates a more favourable environment, explaining the higher SLA of plants grown under more humid conditions (Zhang et al., 2015).

An alternative explanation has also been offered, which does not contradict with the above-mentioned one. Transpiration is not only controlled by stomatal regulation, but also via morphological adaptations. Under conditions that impede water loss, as an increase in RH, plants tend to increase leaf area and decrease leaf thickness in order to offset the decreased transpiration (Giday et al., 2014).

\section{Leaf transpiration rate during cultivation is dominated by $\mathrm{RH}$, with $\mathrm{g}_{\mathrm{s}}$ exerting minor role}

Plants grown (and assessed) at high RH had the highest $\mathrm{g}_{s}$, while plants cultivated at low RH showed the lowest $\mathrm{g}_{\mathrm{s}}$ (Table 1; see also Figure 1B). Contrary to this, leaf transpiration was the highest at high $\mathrm{RH}$, and the lowest at low RH (Table 1; see also Figure 1C). Therefore, leaf transpiration rate is dominated by the level of $\mathrm{RH}$, whereas $\mathrm{g}_{\mathrm{s}}$ exerts a minor role.

Lowering the evaporating demand (i.e., increasing the $\mathrm{RH}$ ) impeded plant water loss during both day time and night time periods (Figure 2). By studying two RH levels (60 and $85 \%$ ), Giday et al. (2013b) reported that changes in plant water loss are principally evident during day time, since night time plant transpiration was not affected by high $\mathrm{RH}$ in most of the assessed cultivars. The broader RH (40 to 90\%) range employed in this study shifted the noted effect to night time too. Studies on potential implications of increased night time water loss for plant physiology are scarce, and thus existing knowledge is rudimentary (Caird et al., 2007). Enhanced night time water loss has been associated with both costs (i.e., prevents equilibration of plant water potential with the wettest soil layer) and benefits (i.e., increased nutrient uptake), depending on the remaining environmental variables (Caird et al., 2007). Although more research will be necessary to reveal the consequences of the substantial night time water loss at $40 \% \mathrm{RH}$, the current data clearly illustrate that night time RH exerts a major effect on plant water relations.

\section{Stomata formed at high RH show a pronounced slowing of opening in response to light}

Oscillations of $g_{s}$ during the light period were very weak in plants developed at high RH (Figure 1B). Although our experiments cannot be employed to analyse the underlying processes, it becomes apparent that the evaporative demand modifies the property of stomata which is responsible for creating the $g_{s}$ variation throughout the day (Mencuccini et al., 2000).

The $\mathrm{g}_{\mathrm{s}}$ rapidly decreased upon transition to darkness in intact plants grown (and assessed) at low or moderate RH (Figure 1B). Instead, high RH-cultivated plants showed a slow and modest stomatal closure following darkening (Figure 1B; Table 2). This indicates that stomata formed at high RH show an attenuated closing response to darkness. Reduced stomatal closure in response to darkness following plant growth at high RH has previously been reported (Fanourakis et al., 2013).

The $g_{s}$ quickly recovered at the onset of the light period in intact plants cultivated (and assessed) at low or moderate
RH (Figure 1B). Instead, high RH-cultivated plants showed a slow opening response at the initiation of the photoperiod (Figure 1B; Table 2). These data clearly illustrate that cultivation at high RH causes a slowing in the rate of stomatal opening in response to light. Thus higher RH not only undermines stomatal closing ability (Giday et al., 2014; Carvalho et al., 2015), but also attenuates stomatal opening. Therefore, the constitutively high $\mathrm{g}_{\mathrm{s}}$ of plants cultivated at high $\mathrm{RH}$ is related to stomata which are more open and at the same time less sensitive to changes in irradiance.

\section{High RH attenuates stomatal closing ability, whereas low RH exerts a promotive effect}

$\mathrm{RH}$ during cultivation determined two basic properties of stomatal closure in response to desiccation (Figure 3B). A stepwise increase in RH during leaf expansion led to both (a) a lower degree of stomatal closure, and (b) a more severe desiccation was needed to induce this response (Figure 3B; see also Table 4). Weak stomatal closing ability in plants cultivated at high $(\geq 85 \%)$ RH is well-documented (Giday et al., 2013a; Fanourakis et al., 2015). Instead, lowering the cultivation $\mathrm{RH}$ to $40 \%$ exerted a striking promotive effect on stomatal closing ability (Figure 3; see also Table 4). Similarly, to our findings, a positive effect of low RH on stomatal closing response has been noted in Arabidopsis thaliana (Pantin et al., 2013; Hõrak et al., 2017). Contrary to this, low RH either did not affect stomatal functioning in Kalanchoë blossfeldiana (Fanourakis et al., 2017), or attenuated stomatal closing response in two fern species (Hõrak et al., 2017). Therefore, the effect of low RH on stomatal functioning very much depends on the species.

Previous work in Rosa hybrida indicates that soil water deficit throughout the cultivation period at $60 \% \mathrm{RH}$ did not affect stomatal response to desiccation (Giday et al., 2014). It is very surprising that air water deficit (i.e., low RH) induced more responsive stomata at ample soil moisture supply (Figure 3), whereas soil water deficit exerted no effect at $60 \%$ RH (Giday et al., 2014). Therefore, the evaporative demand during cultivation in the range of 40 to $90 \% \mathrm{RH}$ is a critical factor determining stomatal closing ability.

It is generally accepted that stomatal malfunctioning noted in plants grown at elevated $(\geq 85 \%) \mathrm{RH}$ is mediated through a long-term decrease in leaf abscisic acid (ABA) concentration ([ABA]; Fanourakis et al., 2016). Leaf [ABA] lower than the one of plants cultivated at moderate $(60 \%) \mathrm{RH}$ negatively affects stomatal closing ability (Giday et al., 2014). Instead, leaf $[\mathrm{ABA}]$ higher than the level of un-stressed plants cultivated at moderate $(60 \%) \mathrm{RH}$, owing to soil water deficit, does not promote stomatal closing ability. Therefore, a direct relation between leaf ABA concentration and stomatal closing ability does not exist (Giday et al., 2014). The absence of this relation has been also manifested in cases where stomatal functioning was improved during cultivation at high $\mathrm{RH}$ by imposing a certain treatment, without any noticeable increase in leaf $[\mathrm{ABA}]$ leading to the suggestion that in these cases stomatal sensitivity to $\mathrm{ABA}$ and/or ABA distribution within the leaf play a role (Fanourakis et al., 2016). To conclude, leaf ABA concentration plays an essential role in stomatal functioning, especially at the lower than the control range, but does not explain all the responses we see. A more comprehensive approach will require measurements of stomatal sensitivity to ABA and within-leaf ABA distribution. Future work that includes the above-mentioned measurements will shed light on the underlying process, explaining the promotive effect of low RH on stomatal functioning. 


\section{Practical implications of seasonal RH variation}

Reduced control of water loss, owing to less functional stomata, has been suggested to underlie the rapid wilting trait of cut roses harvested during the winter months (Fanourakis et al., 2013). This conclusion is also supported by the data of this study (Figures 1 and 3; Tables 2 and 4). We further show that stomata formed at low $\mathrm{RH}$ are much more responsive than the ones developed under $60 \%$ RH (Figure 3; Table 4). This improved stomatal responsiveness to closing cues is expected to promote keeping quality of ornamentals cultivated during the summer period, where RH is typically low.

\section{Conclusions}

Rose plants were grown at 40,60 or $90 \%$ RH. A stepwise increase in RH led to plants with higher leaf area and thinner leaves. The RH level at cultivation was the main determinant of leaf transpiration rate, while differences in $\mathrm{g}_{\mathrm{s}}$ were of minor importance. The higher the RH during cultivation was, the lower the plant water loss. Several stomatal properties were affected by $90 \% \mathrm{RH}$, including reduced oscillations within the photoperiod, attenuated opening response following dark/light transition, as well as impaired closing response upon darkening. Stomata formed at $40 \% \mathrm{RH}$ were more responsive than those formed at $60 \%$. They were able to close more efficiently, and the leaf drying required to induce this response was less severe. The promotive effect of low RH on stomatal closing ability is expected to contribute to the longer keeping quality in the summer.

\section{Acknowledgments}

This work was granted from Aarhus University, and was linked to the project REDHUM (funded by GUDP) as well as to (Interreg ERDF) project GreenGrowing.

\section{References}

Aliniaeifard, S., and Van Meeteren, U. (2013). Can prolonged exposure to low VPD disturb the ABA signalling in stomatal guard cells? J. Exp. Bot. 64, 3551-3566. https://doi.org/10.1093/jxb/ert192.

Aliniaeifard, S., and Van Meeteren, U. (2016). Stomatal characteristics and desiccation response of leaves of cut chrysanthemum (Chrysanthemum morifolium) flowers grown at high air humidity. Sci. Hortic. 205, 84-89. https://doi.org/10.1016/j.scienta.2016.04.025.

Arve, L.E., and Torre, S. (2015). Ethylene is involved in high air humidity promoted stomatal opening of tomato (Lycopersicon esculentum) leaves. Funct. Plant Biol. 42, 376-386. https://doi. org/10.1071/FP14247.

Arve, L.E., Kruse, O.M.O., Tanino, K.K., Olsen, J.E., Futsæther, C., and Torre, S. (2016). Daily changes in VPD during leaf development in high air humidity increase the stomatal responsiveness to darkness and dry air. J. Plant Physiol. 211, 63-69. https://doi.org/10.1016/j. jplph.2016.12.011.

Caird, M.A., Richards, J.H., and Donovan, L.A. (2007). Night time stomatal conductance and transpiration in $\mathrm{C}_{3}$ and $\mathrm{C}_{4}$ plants. Plant Physiol. 143, 4-10. https://doi.org/10.1104/pp.106.092940.

Carvalho, D.R.A., Koning-Boucoiran, C.F.S., Fanourakis, D., Vasconcelos, M.W., Carvalho, S.M.P., Heuvelink, E., Krens, F.A., and Maliepaard, C. (2015). QTL analysis for stomatal functioning in tetraploid Rosa $\times$ hybrida grown at high relative air humidity and its implications on postharvest longevity. Mol. Breed. 35, 1-11. https:// doi.org/10.1007/s11032-015-0365-7.

Carvalho, D.R.A., Fanourakis, D., Correia, M.J., Monteiro, J.A., AraújoAlves, J.P.L., Vasconcelos, M.W., Almeida, D.P.F., Heuvelink, E., and Carvalho, S.M.P. (2016). Root-to-shoot ABA signalling does not contribute to genotypic variation in stomatal functioning induced by high relative air humidity. Environ. Exp. Bot. 123, 13-21. https://doi. org/10.1016/j.envexpbot.2015.11.001.

Fanourakis, D., Heuvelink, E., and Carvalho, S.M.P. (2013). A comprehensive analysis of the physiological and anatomical components involved in higher water loss rates after leaf development at high humidity. J. Plant Physiol. 170, 890-898. https://doi.org/10.1016/j.jplph.2013.01.013.

Fanourakis, D., Giday, H., Milla, R., Pieruschka. R., Kjaer, K.H., Bolger, M., Vasilevski, A., Nunes-Nesi, A., Fiorani, F., and Ottosen, C.-O. (2014). Pore size regulates operating stomatal conductance, while stomatal densities drive the partitioning of conductance between leaf sides. Ann. Bot 115, 555-565. https://doi.org/10.1093/aob/mcu247.

Fanourakis, D., Bouranis, D., Giday, H., Carvalho, D.R.A., Rezaei Nejad, A., and Ottosen, C.-O. (2016). Improving stomatal functioning at elevated growth air humidity: a review. J. Plant Physiol. 207, 51-60. https://doi.org/10.1016/j.jplph.2016.10.003.

Fanourakis, D., Heuvelink, E., and Carvalho, S.M.P. (2015). Spatial heterogeneity in stomatal features during leaf elongation: an analysis using Rosa hybrida. Funct. Plant Biol. 42, 737-745. https:// doi.org/10.1071/FP15008.

Fanourakis, D., Hyldgaard, B., Giday, H., Bouranis, D., Körner, O., Nielsen, K.L., and Ottosen, C.-O. (2017). Differential effects of elevated air humidity on stomatal closing ability of Kalanchoë blossfeldiana between the $\mathrm{C}_{3}$ and CAM states. Environm. and Exp. Bot. 143, 115124. https://doi.org/10.1016/j.envexpbot.2017.09.005.

Giday, H., Fanourakis, D., Kjaer, K.H., Fomsgaard, I.S., and Ottosen, C.O. (2013a). Foliar abscisic acid content underlies genotypic variation in stomatal responsiveness after growth at high relative air humidity. Ann. Bot. 112, 1857-1867. https://doi.org/10.1093/aob/mct220.

Giday, H., Kjaer, K.H., Fanourakis, D., and Ottosen, C.-O. (2013b). Smaller stomata require less severe leaf drying to close: A case study in Rosa hybrida. J. Plant Physiol. 170, 1309-1316. https://doi. org/10.1016/j.jplph.2013.04.007.

Giday, H., Fanourakis, D., Kjaer, K.H., Fomsgaard, I.S., and Ottosen, C.-O. (2014). Threshold response of stomatal closing ability to leaf abscisic acid concentration during growth. J. Exp. Bot. 65, 43614370. https://doi.org/10.1093/jxb/eru216.

Hõrak, H., Kollist, H., and Merilo, E. (2017). Fern stomatal responses to $\mathrm{ABA}$ and $\mathrm{CO}_{2}$ depend on species and growth conditions. Plant Physiol. 174, 672-679. https://doi.org/10.1104/pp.17.00120.

Mencuccini, M., Mambelli, S., and Comstock, J. (2000). Stomatal responsiveness to leaf water status in common bean (Phaseolus vulgaris L.) is a function of time of day. Plant Cell and Environm. 23, 1109-1118.

Mortensen, L.M., and Gislerød, H.R. (2005). Effect of air humidity variation on powdery mildew and keeping quality of cut roses. Sci. Hortic. 104, 49-55. https://doi.org/10.1016/j.scienta.2004.08.002.

Pantin, F., Renaud, J., Barbier, F., Vavasseur, A., Le Thiec, D., Rose, C., Bariac, T., Casson, S., McLachlan, D.H., Hetherington, A.M., Muller, B., and Simonneau, T. (2013). Developmental priming of stomatal sensitivity to abscisic acid by leaf microclimate. Curr. Biol. 23, 18051811. https://doi.org/10.1016/j.cub.2013.07.050.

Poorter, H., Fiorani, F., Pieruschka, R., Wojciechowski, T., Van der Putten, W.H., Kleyer, M., Schurr, U., and Postma, J. (2016). Pampered inside, pestered outside? Differences and similarities between plants growing in controlled conditions and in the field. New Phytol. 212, 838-855. https://doi.org/10.1111/nph.14243.

Poorter, H., Niklas, K.J., Reich, P.B., Oleksyn, J., Poot, P., and Mommer, L. (2012). Biomass allocation to leaves, stems and roots: meta-analyses of interspecific variation and environmental control. New Phytol. 193, 30-50. https://doi.org/10.1111/j.1469-8137.2011.03952.x. 
Rasband, W.S. (2011). ImageJ (Bethesda, MD, USA: US National Institutes of Health). http://imagej.nih.gov/ij/.

Rezaei Nejad, A., and Van Meeteren, U. (2007). The role of abscisic acid in disturbed stomatal response characteristics of Tradescantia virginiana during growth at high relative air humidity. J. Exp. Bot. 58, 627-636. https://doi.org/10.1093/jxb/erl234

Sellin, A., Niglas, A., Õunapuu-Pikas, E., and Kupper, P. (2014). Rapid and long-term effects of water deficit on gas exchange and hydraulic conductance of silver birch trees grown under varying atmospheric humidity. BMC Plant Biol. 14, 72. https://doi.org/10.1186/14712229-14-72.

Zhang, D., Zhang, Z., Li, J., Chang, Y., Du, Q., and Pan, T. (2015). Regulation of vapour pressure deficit by greenhouse micro-fog systems improved growth and productivity of tomato via enhancing photosynthesis during summer season. PLoS One 10, e0133919, https://doi.org/10.1371/journal.pone.0133919.

Received: Apr. 20, 2018

Accepted: Sep. 1, 2018

Addresses of authors:

Dimitrios Fanourakis ${ }^{1}$, Habtamu Giday ${ }^{2,3}$,

Benita Hyldgaard ${ }^{2,4}$, Dimitris Bouranis ${ }^{5}$, Oliver Körner ${ }^{6,7}$, and

Carl-Otto Ottosen ${ }^{2, *}$

${ }^{1}$ Giannakakis SA, Export Fruits and Vegetables, Tympaki,

Greece

2 Department of Food Science, Aarhus University, Kirstinebjergvej 10, DK-5792 Årslev, Denmark

${ }^{3}$ Horticulture and Product Physiology Group, Wageningen University, Droevendaalsesteeg 1, 6708 PB Wageningen, The Netherlands

${ }^{4}$ Department of Bioscience, Aarhus University, Ole Worms Alle 1, DK-8000 Aarhus C, Denmark

${ }^{5}$ Plant Physiology and Morphology Laboratory, Crop Science Department, Agricultural University of Athens, Athens, Greece

${ }^{6}$ Department of Plant Technology, AgroTech, Danish Technological Institute, Gregersensvej 7, DK-2630 Taastrup, Denmark

${ }^{7}$ Leibniz-Institute of Vegetable and Ornamental Crops (IGZ), Theodor-Echtermeyer-Weg 1, D-14979 Großbeeren, Germany

* Corresponding author; E-mail: coo@food.au.dk 